\title{
GUERRA EN EL VALLE DEL EBRO EN LA SEGUNDA MITAD DEL SIGLO XI: GEOESTRATEGIA Y CONTROL MILITAR DE LOS RECURSOS ECONÓMICOS EN EL NORESTE PENINSULAR
}

\author{
WAR IN THE EBRO VALLEY IN THE SECOND HALF OF THE $11^{\text {th }}$ CENTURY: \\ GEOESTRATEGY AND MILITARY CONTROL OF ECONOMIC RESOURCES IN THE \\ NORTHEAST OF THE IBERIAN PENINSULA
}

Darío ESPAÑOL SOLANA

Universidad de Zaragoza despanol@unizar.es

\begin{abstract}
Resumen: La guerra en los albores de la Plena Edad Media hispana alcanzó dimensiones holísticas, pues estaba presente de modo ubicuo en todas sus estructuras sociales y políticas. Durante la segunda mitad del siglo XI, los príncipes cristianos del valle del Ebro iniciarán la conquista del llano, poniendo en marcha estrategias militares de diversa naturaleza no solo contra el Islam, sino entre ellos mismos. Este artículo analiza uno de los aspectos fundamentales para comprender la guerra en ese periodo: la geoestrategia. Y desde una doble perspectiva: la geografía militar y el control de los recursos económicos como base de las acciones militares.
\end{abstract}

Palabras clave: guerra medieval, reconquista, geoestrategia, historia militar, valle del Ebro, siglo XI.
Abstract: The war in the beginnings of the Hispanic Middle Ages reached holistic dimensions, because it was ubiquitously present in all its social and political structures. During the second half of the $11^{\text {th }}$ century, the Christian sovereigns of the Ebro valley will begin the conquest of the plain, starting military strategies of various kinds not only against Islam, but among themselves. This article analyzes one of the fundamental aspects to understand the war in that period: geostrategy. With a double perspective: military geography and the control of economic resources as the basis of military actions.

Key words: medieval warfare, reconquest, geoestrategy, military history, Ebro valley, $11^{\text {th }}$ century. 


\section{Introducción ${ }^{1}$}

El pensamiento estratégico a lo largo de la historia tiene su génesis en la distinción entre la biê — ßín—y la mêtis — $\mu \tilde{\eta} \tau 1 \zeta$ — que hiciera Homero en la Ilíada. La primera alude al sentido estricto de la fuerza y del ímpetu; a la acción de enfrentarse al enemigo directamente. La otra, en contrapartida, propugna el uso de la astucia y la añagaza para conseguir los fines, así como la práctica consciente e institucionalizada del ingenio como arte supremo con el que ganar la guerra. Homero personificaba ambas virtudes en los dos héroes por antonomasia: Aquiles y Ulises (Freedman, 2019: 54). A partir de esta confrontación, la mêtis ocupará un espacio fundamental en el arte de la guerra clásico, cuya resonancia alcanzará a la tratadística ulterior - fundamental para entender la guerra en nuestro periodo- y reverberará permanentemente en el pensamiento estratégico de la Baja Edad Media y la Edad Moderna. En el siglo IV Vegecio es explícito cuando indica que la mejor opción es siempre evitar el enfrentamiento abierto, optando siempre que sea posible por la sorpresa o el golpe psicológico en el adversario. ${ }^{2}$ De similar tenor habla el Strategikon en el siglo VI, haciendo hincapié en la capacidad del strategos para lograr la victoria eludiendo las acciones directas en la medida de los posible. ${ }^{3}$ Los tratados alto y plenomedievales posteriores guardan un mayor equilibrio entre fuerza e ingenio. El Strategikon de Kekaumenos (siglo XI) aconseja al general que actúe con astucia pero también con firmeza, asumiendo que con ambas acciones se ganan las guerras: con el enfrentamiento directo y con la estratagema. ${ }^{4}$ Al-Harawi (siglo XII) también exhorta en similares términos, pero una lectura general de su tratado denota su inclinación hacia la manipulación de la debilidad del enemigo y al aprovechamiento del ingenio como herramienta para lograr la victoria, considerado más valioso que la propia fuerza mal desperdiciada.

1 Este trabajo forma parte del proyecto de tesis doctoral en curso: Guerra y cultura militar del valle del Ebro en los siglos XI y XII. Musealización y didáctica de la guerra en la Edad Media, cuyo depósito y lectura está prevista para finales de 2020 y está dirigida por los profesores Dr. Juan F. Utrilla, de la Universidad de Zaragoza y el Dr. Nayra Llonch Molina, de la Universitat de Lleida.

2 De Re Militari, libro II, [VIII].

3 «El strategos deseable es aquel que antes de entrar en combate estudia cuidadosamente al enemigo, y puede protegerse contra sus puntos fuertes y tomar ventaja en sus debilidades»: Strategikon, libro VII, parte A [Preámbulo]; «[...] especialmente al inicio de la invasión debemos estar seguros de no entablar con ella una batalla campal. En lugar de eso, debemos cuidadosamente montar emboscadas por el día y por la noche, bloquear la ruta que está tomando el enemigo, ocupar de antemano los puntos fuertes y destruir los suministros a lo largo de la línea de marcha». Ibídem, libro X, cap. II.

4 Kekaumenos, VI, 2, [ii]. 
Parece, pues, que la tradición tratadística identifica desde antiguo el propio desempeño de la estrategia con la mêtis, es decir, el modo de concatenar acciones que permitan la consecución de los objetivos militares sacrificando cuantos menos recursos mejor. Es lo que Liddle Hart identifica con las estrategias de aproximación indirecta. La duda radica en conocer si los príncipes cristianos y musulmanes diseñaron las operaciones de guerra y conquista instruidos en este pensamiento estratégico recogido por la tratadística. Para algunos autores la identificación de acciones y estrategias reconocibles en los tratados respondería más a soluciones lógicas dadas en tales momentos que a una aplicación sistemática de estos magisterios (Guveira Monteiro, 2009; Morillo, 2002).

La Geoestrategia es una disciplina reciente, subsidiaria de la Geopolítica y de la propia Estrategia militar. Si bien es cierto que tomó forma en el pasado siglo XX entre los subcampos de la ciencia militar, su procedencia se ha ido construyendo desde diversas ópticas que han aunado los postulados más clásicos de la geografía con el de la estrategia y otras áreas de estudio militares. No existe un consenso sobre su definición. Celilier dice de ella: «La Geoestrategia, hermana menor de la Geopolítica, forma con ella un homogéneo díptico que de este modo ofrece al político y al militar igual método de aproximación a los problemas necesariamente conexos en el mundo actual» (Celilier, 1979: 51). Por tanto, parece razonable hilvanar en su constructo la política y la guerra. Hacia un mayor acercamiento conviene entender que «la geoestrategia es la interpretación estratégica de la geografía, así como la geopolítica es la interpretación política de la misma realidad» (Bolivar Ocampos, 2012: 27). En cualquier caso, geografía y estrategia militar son elementos que siempre han ido de la mano. Aunque su mixtura como campo de conocimiento sea reciente, las planificaciones militares del pasado han necesitado de la consideración y del conocimiento del paisaje y la orografía para su desarrollo.

\section{La consideración de una geografía militar en el siglo XI}

La documentación catalana del siglo XI es pertinaz en el uso de fórmulas jurídicas que traslucen el modo de concebir el territorio en la Edad Media. La expresión [...] de tuos kastros aut kastellos, rochas vel puios, condirectos vel heremos, terra et honore, alodes vel fevos, comitatus vel comitatu [...] se repite en decenas de documentos, procedentes de distintas manos y de distintas instituciones. El ánimo por nominar a la tierra de modo holístico para un efecto estrictamente jurídico deja aquí una impronta de la consideración espacial en la mentalidad de la Plena Edad Media. 
El hombre medieval entendía el medio geográfico a partir de una dualidad irrefutable, que a su vez resultaba aplastantemente utilitaria y lógica. Por un lado, el espacio sometido, dominado, accesible. Por otro, el inculto o que era incapaz de controlar. Heremo vel populato. El concepto de ordenación del territorio actual es ajeno al pensamiento medieval; la consideración territorial como superficie medible, ordenable o abarcable se presentaba como un constructo peregrino. Este mismo territorio natural, a la sazón, incluso coqueteaba con el imaginario colectivo vinculado a lo inhóspito de lo desconocido (Castro Hernández, 2015: $30)$. No es menos cierto, empero, que desde el propio siglo XI las sociedades medievales cristianas asisten a una evolución del propio concepto (Souvirón Bono, 2012: 316). El hombre parece ir desquitándose del paradigma ideológico altomedieval que considera el territorio como un todo integrante de la creación divina y la configuración del mundo, para acercarse a él desde presupuestos más terrenales que van a rodearse de concepciones científico-filosóficas.

Ahora bien, la forma de interpretar el mundo puede acercarnos al pensamiento que pergeñó las estrategias militares en un tiempo determinado, pero se antoja necesario descender hacia evidencias o pesquisas más funcionales si queremos acercarnos a una realidad pragmática. En términos de geografía militar, lo conquistable es aquello que el hombre domina. Bien es cierto que jurídicamente hablando este no se olvida del yermo - todo lo que no está ocupado o construido-, porque en algún momento puede llegar a dominarlo y por tanto constituir sujeto jurisdiccional. Pero el interés estratégico se centra sobre los espacios antropizados. Cuando el yermo fija el interés del hombre es porque se hace necesario controlarlo como paso previo para conquistar algo habitado, construido y/o transitable.

La inexistencia de pensamiento cartográfico en el periodo feudal hace que se conciba el territorio como un constructo colectivo de límites difusos, ${ }^{5}$ pero en términos efectivos se interpreta como una amplia retícula de puntos conectados cuya naturaleza es sináptica. Cada uno de estos puntos - ciudades, villas, castillos, mansos, almunias, atalayas...- ejerce influencia antrópica sobre un área circundante que se describe en términos cualitativos y no

5 En los siglos XI y XII, la «paquetización» del territorio tendrá coordenadas muy generalistas y siempre bajo parámetros no cuantitativos. La documentación es muy clara. Por ejemplo, en 1122 Alfonso I libera a los habitantes del valle de Hecho de herbazgo de Monçon usque ad Montecayo: CDAI, doc. 112, [1122.VI]. O lo vemos también en la especificación que hace Pedro I del territorio dependiente del castillo de Monzón posteriormente a su conquista, cuyos límites se establecen a partir de lugares y no de referencias geográficas: CDPI, doc. 11, [1092.VI]; también en PACBI, doc. 239, [1092.VI]. 
mensurables. ${ }^{6}$ Asimismo, los límites de la propiedad no se construyen en base a unidades de medida, sino a partir de referencias concretas - afrontaciones o propiedades colindantes - . Cuando la documentación alude a unidades de medida — cuantitativas - en relación a superficie o área, estas siempre son utilitarias y relativas — caso de la yugada o la parasanga —, nunca matemáticas o cartográficas. ${ }^{7}$ El estimulante reto del historiador militar consiste en delinear unos parámetros mentales que permitan a su vez comprender cómo se planificaba la guerra y la conquista del territorio sin representaciones gráficas del espacio terrestre. No existió modo de comprender la realidad espacial a través de la cartografía; los mappae mundi no eran fines en sí mismos, sino representaciones mentales con propósitos didácticos (Souvirón Bono, 2012: 323) que recogían «la geografía virtual de la Biblia» y «los jirones de erudición clásica que todavía continuaban prendidos en la memoria colectiva» (Tyerman, 2019: 439).

La información geográfica en los siglos XI y XII constituía un universo discursivo que aunaba elementos profanos con legendarios, y que para territorios concretos se organizaba a través de factores empíricos recolectados a partir de conocimientos que se transmitían de forma oral o por escrito. La experiencia de los viajeros, las narraciones o el conocimiento de los actores locales construían esta sabiduría, y a partir de ella se edificaba cualquier empresa que debiera desarrollarse en el territorio. También la guerra. Ese medio antrópico vertebrado reticularmente se comunicaba entre sí mediante itinerarios de viaje, tiempos de desplazamiento y etapas, para el caso de las rutas principales (Ferreira Priegue, 1994: 48). El ejemplo más evidente lo tenemos en las obras de los grandes geógrafos andalusíes.

Pero la actividad militar se amparaba frecuentemente en el conocimiento de rutas secundarias, caminos, veredas, senderos de bosque, puentes, pasos de montaña, vados y lugares para cruzar ríos, o en noticias relevante sobre topografía o vientos dominantes. ¿Cómo trazar una estrategia militar sin ese conocimiento, que contemple tiempos de desplazamiento, características de las vías, caudales de los ríos y tantas otras variables? La procedencia de las noticias podía ser variada y las fuentes lanzan frecuentes guiños para la realidad hispana y

6 Cuando se definen territorios en términos jurisdiccionales, los criterios tampoco son geográficos o espaciales, sino poblacionales. Así, por ejemplo, cuando Sancho Ramírez delimita la jurisdicción de la iglesia de Monzón (CDSR, doc. 110, [1089.VIII]) enumera lugares y sus términos —es decir, áreas de influencia antrópica-, no realidades geográficas o demarcaciones fronterizas tangibles. Es un ejemplo de tantos.

7 Qué duda cabe que este concepto de territorio afecta a los propios constructos de reino y de frontera, muy alejados de la noción contemporánea — de la que nos cuesta tanto desquitarnos- establecida tras el advenimiento del Estado liberal y propia de los estados-nación actuales. 
en concreto para el valle del Ebro. La existencia de guías entre la tropa es permanente ${ }^{8}$ y debieron constituir una pieza clave en toda planificación, bien asesorando a los generales o incluso estando presentes en la misma. ${ }^{9}$ Pero no constituyeron el único recurso. No debemos desdeñar la información que podía recaudarse a partir de las noticias de los propios comerciantes, de los espías y agentes de inteligencia infiltrados, de los prisioneros liberados y de toda actividad militar precedente. De hecho, la gran cantidad de menciones a cautivos que la documentación muestra nos está indicando la existencia de un permanente trasiego de prisioneros, como ha sido ya documentado anteriormente. Por lo que es necesario pensar que la cautividad constituyó, en el fondo, una fuente de información — no solo geográfica — muy necesaria para la guerra.

Sin obviar el poder de un elemento recurrente en la guerra medieval, que lejos de constituir únicamente un recurso de guerra de desgaste, dotaba a comandantes de algo más valioso: información geográfica. Nos referimos a la cabalgada. El movimiento de tropas a caballo, más o menos numerosas, fue una herramienta de gran valor porque cumplía funciones de reconocimiento del terreno. No es extraño, consecuentemente, ver a príncipes cristianos de tanto en tanto comandar estas cabalgadas, ${ }^{10}$ pues a la sazón el conocimiento del territorio por parte del líder era fundamental para establecer las estrategias. Tradicionalmente se ha venido arrogando a las cabalgadas señeras intenciones de desgaste y obtención de botín, pero en las acciones rápidas sin caravanas o acémilas, el botín en especie es difícilmente transportable.

8 Una constante en los ejércitos musulmanes, como demuestran las fuentes con frecuencia. En el siglo X an-Nasir se valía de los guías para todo desplazamiento militar: «[...] ordenó a los guías que indicasen el camino más apropiado y cómodo para los musulmanes, que llevaban las acémilas muy cargadas [...]», dice Ibn Hayyan de la campaña de Alhándega: Al-Muqtabis V, p. 331.

9 En 915, el rey Ordoño de León emprendió una algara contra a zona de Mérida y para ello ordenó a su ejército que siguiera a dos guías musulmanes que sabían por donde cruzar el Guadiana e internarse en el llano. Pero los dos guías les hicieron dar un rodeo por la vera del río, haciendo perder un tiempo valioso al ejército cristiano que permitió a las poblaciones musulmanas precaverse ante la llegada de los invasores: Al-Muqtabis V, p. 101. El pasaje nos da una idea de la facilidad con que el enemigo desconocía el territorio objeto de ataque, y de la confianza con que se investía a estos personajes durante las campañas. Notorio es también el episodio de los mozárabes andalusíes que ejercieron de guías por el territorio durante la campaña del Batallador en 1125 (Lema Pueyo, 2008: 201).

10 Los reyes de Aragón extendieron documentos en medio de cabalgadas o acciones militares en territorios que nos hacen barruntar frecuentes acciones de naturaleza depredadora o de reconocimiento: [...] inter Montson et Pomar, ubi erat rex prefatus cum sua oste iniuncta de damnum de Caesaraugusta et de damnum de Lerida, dirá Sancho Ramírez en 1083: CDSR, doc. 64, [1083.VI]; [...] ubi eramos in hoste de Almunien, escribía en 1102 Pedro I: CDPI, doc. 113, [1102.V]. Se trata de acciones que parecen preceder a conquistas y acciones militares ulteriores. 


\section{Accidentes geográficos y guerra}

Durante el califato una de las constantes fue la dificultad del ejército califal para soslayar orografía accidentada, algo que también parecen replicar los ejércitos de las taifas del valle del Ebro. Tal parecen indicar las acciones de socorro sobre plazas perdidas situadas a pie de sierra, en mayor medida que las que estaban ubicadas en el interior de valles o entre cadenas montañosas. La constitución de un ejército de devastación acostumbrado a acciones rápidas y profundas de desgaste en lugar de acciones de conquista concurre en planificar largas travesías, por lo que el grueso del ejército debe viajar con la impedimenta y sus acémilas. Algo que acarrea problemas para franquear vados o atravesar barrancos y que se muestra como una ventaja para un enemigo aprovisionado y con bases logísticas próximas; a pesar, no obstante, de que la tratadística coetánea describe cómo actuar en tales supuestos. Así se evidencia en el desastre de Simancas de 939, cuando los cristianos aprovecharon el paso de las tropas de an-Nasir por un barranco para tratar de dividir y hostigar al grueso desde su vanguardia. ${ }^{11}$ Fue una constante de los ejércitos andalusíes, no obstante, el interés por hacer la batalla en el llano, ${ }^{12}$ algo que condicionaría su falta de predisposición para hacer la guerra en valles o territorios montañosos.

11 Al-Muqtabis V. p. 332. Tanto el Strategikon de Mauricio como el Taktika de León VI aconsejan con denuedo no atravesar barrancos, y de hacerlo colocar batidores en lo alto de cimas escarpadas, fondos y accesos. Conminan a ubicar la impedimenta en el medio del contingente, nunca en la vanguardia o en la retaguardia. Por ende, siempre indican que nunca se debe iniciar el paso de un barranco o garganta sin tener pleno conocimiento de lugar exacto en el que se encuentra el enemigo, sea acuartelado o en movimiento. Strategikon, libro IX, cap. 4; y Taktika, cap. IX. No obstante, el recurso de este tipo de orografía como accidente activo también se ha utilizado en ocasiones a lo largo de la historia. Cf. Stratagemata, cap. IV. De tenor similar habla al-Harawi, aconsejando el uso permanente de exploradores en todo movimiento de tropas y no dividiendo el ejército bajo concepto alguno durante la marcha. (Ad-Tadkira, cap. XVI). Ibn Hudayl, al respecto, aconsejaba al general que evitase los terrenos accidentados si se está a la defensiva, escogiendo suelos de buen piso para caballos y hombres. (Ibn Hudayl I, p. 204).

12 Cinco años antes (934), en la Campaña de Osma, la batalla que se desarrolla entre las tropas del rey Ramiro II de León y an-Nasir en al-Mamliyya es una muestra del denodado interés por parte de los caídes andalusíes por lograr que las tropas cristianas desciendan de las lomas para entablar combate en campo abierto. Lo que al final consiguen y les da la victoria. Al-Muqtabis V, pp. 255-256. Este ejemplo describe muy bien la lección de Vegecio, que dice: «Cuando te dispongas a entablar combate procura gozar de la ventaja inicial de tu posición, que se considera más favorable cuanto más arriba se ocupe. [...] Quien ataca cuesta arriba mantiene un doble enfrentamiento, contra el lugar y contra el enemigo». Todo parece indicar que el interés de los caídes islámicos por enfrentar en el llano se debió a una superioridad de la caballería como elemento axial, un comportamiento que este autor ya proponía: «[...] si pretendes vencer a la infantería rival con tu caballería debes buscar terrenos algo más elevados pero llanos y despejados [...]». De Re Militari, libro III, XIII. 
Incluso el uso de la orografía puede darnos las claves del genio militar de los líderes, definiendo modelos o tendencias tácticas y estratégicas. Alfonso el Batallador era dado a 'castramentar' a los pies de una loma, colocando seguramente batidores en su parte más elevada y usando el accidente como elemento de protección, ${ }^{13}$ como por ejemplo durante la campaña que llevó a cabo en Al-Ándalus entre 1125 y 1127. El uso de los accidentes por parte de los líderes de modo deliberado es una constante, siempre según las condiciones del enemigo y las posibilidades propias. En esa misma campaña, el gobernador Tamim, hermano del emir Alí ibn Yusuf, mandó mudar el campamento de la protección de una hondonada a la cima de una colina durante las escaramuzas con el Batallador en la Batalla de Arnisol. ${ }^{14}$ Unas acciones que tienen su reflejo en la sabiduría militar. Así lo demuestra Al-Hulal al-mawsiyya con el poema en forma de loa y consejo que el ulema Abu Bakr ibn al-Sayrafi dedicó a Yusuf ibn Tasufin, entre cuyos versos le indicaba rodearse de un foso al plantar el campamento, aunque estuviera persiguiendo al enemigo o fuese él el perseguido; que no dejase río detrás de sí cuando se encontrasen con él; y que dispusiera el combate, a ser posible, al atardecer, dejando detrás de sí un desfiladero que pudiera ser bien defendido. ${ }^{15}$

Si nos centramos en la expansión feudal en el valle del Ebro durante la segunda mitad del siglo XI, sin duda las protagonistas fueron las sierras exteriores del Prepirineo. Esta muralla calcárea constituye un sistema kárstico resquebrajado por barrancos y cauces, por la que los afluentes del Ebro se han ido abriendo paso perpendicularmente desde hace millones de años entre valles y simas, creando una barrera natural de complejo franqueo. Durante el siglo XI los reyes y señores feudales evidencian una preocupación «estatal» por comunicar de forma transversal este territorio complejo ${ }^{16}$ lo que demuestra que el principal pro-

13 Las crónicas nos muestran varios ejemplos, como en CEP, p. 127. Los tratados no la sancionan como una práctica negativa, siempre que el lugar elevado no pueda ser usado por el enemigo y pueda ser defendido —De Re Militari, libro I, XXII—, por lo que entendemos que lo que elegía Alfonso I eran los pies de lomas escarpadas de imposible acceso.

14 Al-Bayan III, p. 165. Es muy probable que Tamim pretendiese hacer uso de su caballería para defender el campamento en caso de ser atacado y por las razones antes esgrimidas.

15 Al-Hulal, p. 152.

16 En su primer testamento, Ramiro I dividió en tres partes sus posesiones, una de las cuales exigía que se emplease pro cabtibos et pro pontes facere et ad castros de fronteras de mauros qui sunt pro facere, CDRI, doc. 134, [1054.VII.29]. Fórmula que repite en su segundo testamento, en 1061: [...] et de alios meos barones sedeat totum datum et partitum per mea anima, per monasterios et in labores de pontes facere, et per captivos redimere, et in castellos de fronteras de mauros qui sunt per fare unde prodesit de christianis totum, sic sedeat datum et partito per mea anima, CSJPII, doc. 158, [1161. 
blema de la planificación militar fue una logística que presentaba demasiados inconvenientes. ${ }^{17}$ En una orografía como tal, los tiempos de recorrido varían, las etapas se acortan, los caminos son estrechos y las distancias visuales se difuminan o se condicionan a variables como la altitud, la climatología o la accesibilidad. Las estaciones logísticas también deben reconsiderarse. De igual modo, tienden a apocoparse o concentrarse los puntos estratégicos, dado que se simplifican las vías y los pasos cuanto más difícil es el territorio.

\section{El control de los recursos económicos en la guerra plenomedieval}

Dentro de la geoestrategia es necesario también prestar atención a un elemento capital que define en cierto sentido la propia naturaleza estratégica del enfrentamiento armado. Se trata del control de los recursos económicos como parte del conflicto. Consuetudinariamente se ha tendido a historiar el hecho militar motivado $-\mathrm{y}$ englobado- por las propias dinámicas feudales. Se ha concebido la expansión y la inversión de recursos militares en aras de la consecución de objetivos como consecuencia de todo lo interrelacionado con la maquinaria feudal, ${ }^{18}$ pero sin reparar en fundamentos más propios de una realidad

II.28]. Equiparar en el mismo deseo redención de cautivos, construcción de puentes y edificación de castillos es la evidencia de la problemática latente de una política de guerra. La fórmula se repite en otros testamentos, siempre procedentes de la titularidad real o condal. La viuda de Ramón V de Pallars dejaba una de las cuatro partes de sus posesiones per captivos et per pontes, PACBII, doc. 398, [10981100.II.19]. En 1131 el vizconde Guerau de Cabrera hizo otro tanto: [...] pro anima mea in missas et in pontibus uel captiuis aud ecclesiis et ubi melius uiderint, soluti mei debiti, CDSPAI, doc. 267, [1131. VII.4]. Nótese que esta fórmula parece prevalecer en principados cuyos territorios se extienden por regiones accidentadas. Aunque no es menos cierto que constituyó una fórmula no solo propia de alguna titularidad «estatal», pues también la encontramos en los deseos testamentarios de la baja nobleza: $E t$ aliud date sacerdotibus et pontibus et captivis et ubi melius videritis ad salvamentum de mea anima, DECCRI, doc. 170, [1122.IV.24].

17 En algunos casos la comunicación del territorio alcanzaba puntos de verdadera importancia estratégica, como en el caso de la unión del río Asabón con el Gállego, que daba acceso a la entrada pétrea que constituían Riglos y Agüero. Así lo demuestra el propio Ramiro I en su testamento, en el que insistía en que si illo ponte de Kakauiello non fuerit complito de ipsum se compleat, CDRI, doc. 134, [1054. VII.29]. El citado puente debió situarse a los pies del castillo de Kakabiello, actualmente sumergido en el pantano de La Virgen de la Peña. O el testamento de Arnau Mir de Tost, en el que indica [...] et aliam terciam parte dimitto ad ipsum pontem de Nogera quem ego et uxor mea iam cepimus, CDSPAI, doc. 99, [1072.VIII.11]. No especifica de que puente se trataba, pero su ocupación o conquista debía constituir importancia estratégica, de ahí el interés por invertir en su reparación y mantenimiento.

18 Con independencia de que esta, a su vez, estuviera motivada por un expansionismo demográfico, económico e incluso ideológico. 
estrictamente militar. Desde una perspectiva militarista, pues, sin menoscabo de que tales pretextos constituyeran fines últimos en sí mismos, los teatros de operaciones obligaban a los estrategas feudales a interpolar movimientos y decisiones movidos por cuestiones más pragmáticas y cotidianas. Somos conscientes de que la finitud de las fuentes es un obstáculo para reflexionar sobre la motivación real de cada acción militar, de cada propuesta de conquista; pero la guerra a la largo de la historia se ha movido por objetivos militares menos idealistas y más funcionales. Es aquí cuando se esparcen sobre el tapete aspectos relacionados con el dominio de los recursos económicos, o con el control y bloqueo de comunicaciones fluviales y terrestres, entre otros aspectos.

Este es un tema que todavía no ha sido plenamente bien abordado para nuestra época. La parquedad de las fuentes, en todo caso, nos obligaría a historiar este asunto de forma comparada, echando mano de la constatación de indicios, la problematización activa y seguramente el apoyo de otras disciplinas, ajena alguna de ellas a las propias Humanidades. Como se expondrá más abajo, es complicado considerar — a riesgo de que resulta una obviedad - si junto a las pretensiones de conquista clásicas contra una u otra plaza existieron otras motivaciones inherentes al éxito del propio conflicto: la obtención de recursos — mineros, acuíferos o saliníferos ${ }^{19}$ —; la interceptación de tradicionales rutas de paso o comercio; o el acceso a espacios de alto nivel económico como consecuencia de la obtención de conocimiento previo a la conquista. ${ }^{20}$

García Fitz ya incluyó acertadamente la dimensión económica imbricada entre los objetivos de las acciones militares, fundamentalmente en las de desgaste (García Fitz, 1998: 90-100). Es evidente que el leitmotiv último de toda campaña bélica es el económico, así como los que de él se derivan o se interrelacionan. ${ }^{21}$ De hecho, se puede identificar en cualquier conquista un interés por la propia expansión de las élites dirigentes. ¿No es esa, realmente, una motivación

19 Entre otros. En 1063 al-Mu'tadid de Sevilla establece una estrategia en la que corta los aprovisionamientos de leña y carbón hacia el territorio del señor de Silves: CART, [13], p. 35.

20 La constancia de realidades económicas o espaciales de bienes y territorios en la planificación estratégica es recurrente en la documentación. Alfonso II, por ejemplo, da a Calbet de Biel en 1166 tres heredades en el castillo de Albarracín, aún por conquistar. El texto describe todo el continente de las mismas, identifica con claridad a sus dueños andalusíes actuales o los tipos de explotación agraria que albergan. Se trata de una descripción de la propiedad para nada superficial, con su posible validez de renta futura, sus unidades y sus elementos muebles e inmuebles: DAII, doc. 35, [1166.IX.7]. A despecho de cuestiones sobre inteligencia, es obvio que la información sobre recursos formaba parte del concurso de la estrategia militar.

21 La triada clásica que motiva el enfrentamiento bélico, dirá Andreski: power, wealth and prestige (Andreski, 1968: 10). 
económica en sí misma? Pero cuando aludimos a objetivos económicos lo estamos haciendo desde una panorámica coyuntural, insertos en la propia dinámica de la guerra emprendida; más relacionados con su tratamiento estratégico para favorecer la propia capacidad o dañar la del enemigo que con fines expansivos en sí mismos. Y a sabiendas de que se trata de un tema de investigación y análisis muy jugoso, cuyo tratamiento en profundidad trascendería las limitaciones - y metas - de este artículo, conviene reflexionar sobre los recursos por antonomasia, que no fueron ajenos a la estrategia militar del periodo: el oro y la sal.

\section{La fiebre del oro}

Los siglos VIII y IX vieron cómo Al-Ándalus reacuñaba dinares a partir del numerario visigodo y bizantino (De Villar Iglesias, 2016: 185). 'Abd al-Rahman III, ya en el siglo X, trazará una política para cambiar esto y controlar la producción aurea africana canalizando su suministro hacia la Península Ibérica. ${ }^{22}$ Desde ese momento la moneda andalusí alcanzará una pureza del $90 \%$ (De Villar Iglesias, 2016: 250), jamás antes conocida. El oro se convirtió en uno de los elementos de legitimación califal, no solo porque posibilitó el saneamiento del tesoro estatal, sino porque incrementó el acceso a la riqueza y los intercambios comerciales. Todo este oro procedía de las minas del Sudán Occidental ${ }^{23}$ y para lograr su flujo y recepción el califa omeya pergeñó una política de control de las tribus bereberes a fin de garantizarse el abastecimiento del metal precioso a través de las rutas que partían desde sus minas y recorrían el Sahara y el Magreb hasta llegar al Estrecho. ${ }^{24}$

22 Para conocer el volumen y estadísticas de acuñación de moneda durante el emirato y el califato: Ibrahim y Gaspariño, 2016.

23 El oro africano no debió ser el único que abasteció a Al-Ándalus. No habría que desdeñar la aportación de yacimientos hispanos, dada la ingente cantidad de numerario que se puso en circulación durante el califato. Cf. Canto García y Cressier, 2008: XI-XIX. Sin ir más lejos, en la denuncia de Ibn Hazm contra los impuestos indebidos que cobran los reyes de taifas, se nombra a los hombres libres que extraen oro en minas de la propia zona de Lérida (Asín Palacios, 1934: 40-41). No obstante, a pesar de constatar la abundancia de minas metálicas en la Península, la arqueología no ha podido conocer hasta qué nivel industrial estas minas fueron explotadas (Domerge, 2008: 251-252). Los especialistas coinciden en aceptar que en algún momento de la Alta Edad Media el complejo y profuso sistema de extracción minera romana debió truncarse (Echevarría Arsuaga, 2010: 57). Ahora bien, no está claro de qué modo influyeron en el abastecimiento industrial los recursos mineros propios una vez se dio el establecimiento arabo-islámico en la Península.

24 De Villar identifica tres grupos de rutas: las del Sahara Occidental, las del Sahara Central y las de Magreb, teniendo las principales ciudades caravaneras como hitos de recepción y expedición de estas (De Villar Iglesias, 2016: 387-483). 
Sin embargo, el control de las rutas caravaneras desató el conflicto entre Al-Ándalus y el califato fatimí..$^{25} \mathrm{La}$ guerra por la fiebre de oro subsahariano se extendió durante las décadas centrales del siglo $\mathrm{X}$, hasta que los fatimíes trasladaron su capital a Egipto en 969. En un principio, 'Abd al-Rahman III conquistó Ceuta y Melilla y estableció un protectorado en el Magreb atrayéndose a la confederación de los Zanata y otros Estados, pero los fatimíes respondieron controlando las principales ciudades caravaneras. Más tarde, con la amenaza fatimí atemperada, Al-Hakam II y Almanzor consolidarán el poder andalusí sobre este territorio, garantizando el abasto de esclavos y oro hacia la Península.

Todo esto se truncó con la llegada de la fitna. Tras la disgregación del califato, las taifas asistieron a una verdadera crisis del oro y también de la plata. Las líneas de suministro con el Magreb se cortaron y la calidad de la moneda decayó (Prieto y Vives, 1926: 95-102) desde las primeras décadas del siglo XI. ${ }^{26}$ Solo siguieron acuñando moneda de oro de buena ley los hamudíes, fundamentalmente porque ganaron la fidelidad de parte del Magreb, manteniendo los resquicios de estas rutas (De Villar Iglesias, 2016: 252). Sin embargo, esto contrasta con una sociedad andalusí ávida de este metal precioso. Las taifas requirieron durante su existencia perentoriamente de metales nobles para la acuñación de moneda, como elemento de legitimidad emiral y a causa del drenaje constante de los reinos cristianos de este metal en forma de parias. La adquisición de oro y plata iba a redefinir en lo sucesivo el teatro de operaciones y, por consiguiente, la estrategia militar.

En el caso de los emires de las taifas, el monopolio y gestión de las rutas comerciales con el Magreb por parte del poder califal en el siglo X había eximido a sus antecesores de muchas preocupaciones en lo que concierne a su circulación en Al-Ándalus y sus demarcaciones. Para los embrionarios principados feudales, con excepción del condado de Barcelona, la entrada de oro había sido hasta ese momento exigua y testimonial. ${ }^{27}$ Pero en este momento la coyuntura se invierte y el oro va a entrar de lleno en la planificación estratégi-

25 Sobre el conflicto, oro y política monetaria: Ibrahim, 1990.

26 Las alteraciones metrológicas y el desplome de la ley de las monedas fue una constante. Desde ese momento la pureza de dinares y dírhams descendió hasta casi un 30\%, y la baja ley de los dirhams los convirtió en moneda de vellón, por lo que se evidencia también la crisis del abastecimiento de la plata (De Villar Iglesias, 2016: 237).

27 No se conoce amonedación en toda la primera mitad del siglo XI ni en Pamplona, ni en Aragón, ni en León, ni en Castilla (Utrilla Utrilla, 2006: 543). 
ca peninsular. Los poderes islámicos tuvieron que importarlo de manera individual, pues las rutas que abastecían al califato se habían desviado o ya no existían, de modo que solo quedaba reacuñar, batir con menos ley y encarar la geopolítica a través de una estrategia que permitiese su adquisición, lo que también implicó adscribirse a la advocación de uno y otro califa según se garantizase con ello una estabilidad comercial y un aprovisionamiento de metales preciosos. ${ }^{28}$ Sin embargo, la codicia de los reyes y condes cristianos entró en ese juego.

¿Dónde estaba, pues, ese oro que marcó el devenir estratégico en el sector nororiental de la Península? Qué duda cabe que una parte procedía del periodo anterior, en el que los metales preciosos habían abundado. ${ }^{29}$ Bastaba con reacuñar sobre numerario califal. Pero es evidente que este relativo superávit no fue suficiente. A partir de los últimos años de la fitna el volumen de acuñaciones de los distintos poderes taifales, así como su ley y sus características, experimentaron un proceso de calidad a la baja y con intermitencias. Ya bien entrado el siglo XI mantuvieron una cierta calidad las monedas de las taifas de Sevilla y Zaragoza, las de los hamudíes y en menor medida las de las taifas de Levante. ${ }^{30}$ Anteriormente, entre 1009 y 1031, este fenómeno se observa en las monedas de hamudíes, de Muyahid en Denia y de los saqaliba, Mubarak y Muzaffar, en Valencia — de plata—; todo parece indicar que estos gobernantes lograron

28 Hacia mediados del siglo XI la invocación califal se polarizó, tal como nos informa Ibn Idari a través de Ibn Hayyan. Sulaiman ibn Hud; Ibn Abbad de Sevilla; Muqatil de Tortosa; 'Abd al-'Aziz el amirí, de Valencia; Muyahid de Denia; Ibn al-Aftas de Badajoz; Yahya ibn Di-n-Nun — con renuencias iniciales y en guerra con Zaragoza- y otros señores menores del Levante y del sur invocaban a Hisham, alzado en Sevilla. Frente a ellos, los emires bereberes del sur, a cuya cabeza estaba Badis de Granada, lo hacía con Idris, el hamudí alzado en Málaga. Al-Bayan I, pp. 183-184. Nótese que dirigir la jutba hacia uno de estos señores era asegurarse también el flujo de oro, pues abadíes y hamudíes habían heredado la importación de metales preciosos tras la fitna, como demuestra el hecho de que eran los únicos que mantenían una cierta calidad en sus amonedaciones junto a zaragozanos y levantinos.

29 Las fuentes evocan muy frecuentemente el constructo ideológico bien conocido de que los principados cristianos consideraban a hispanomusulmanes ricos y acumuladores de riquezas. De hecho, parece el pretexto inicial con el que estos comenzaron a exigirles tributos. La incapacidad de los poderes cristianos por acceder inicialmente a las rutas de los metales preciosos controladas por el Islam, hizo de esta práctica la principal como método para hacerse con ellos. Quizás el pasaje más sintomático es el que narra Ibn Idari entre los habitantes de Toledo y Fernando I del Castilla. Cf. Al-Bayan I, p. 233.

30 A las evidencias arqueológicas se suman los términos con que designan a las monedas de oro y plata en la documentación catalana y aragonesa: aparecen los ceptis (hamudíes) — de Ceuta, Madina Sabta - , los denescos — de Denia-, los almanzores, sarakusties o saragencianos — de Zaragoza-o la moneda acuñada en Valencia. Sin duda la circulación de este numerario en transacciones comerciales y entre las élites del valle del Ebro - y también entre capas populares para el caso catalán, según Bonassie — nos está indicando la pujanza y capacidad de emisión de moneda de estos poderes (Bonassie, 1987: 171-173). 
mantener durante la fitna un flujo de metales preciosos africanos hacia sus cecas. Los hamudíes por el poder que supieron extender sobre el Magreb; en el caso de Denia y Valencia, por su capacidad marítima y portuaria.

Pero después el desplome de la ley en las acuñaciones fue general. Solo batieron dinares de oro de cierta calidad a lo largo de siglo XI los abadíes sevillanos y los tuyibíes y hudíes zaragozanos. En el caso de los primeros, la falta de plata (Grañeda Miñón, 2008; Ariza Armada, 1995: 234-235) hizo que el oro fuese para ellos el metal de referencia en las acuñaciones, lo que hace barruntar que durante todo esta centuria continuaron conectados a las rutas del oro sudanés a través de los puertos del Estrecho. En el caso de los emires zaragozanos, sus conexiones de invocación califal con Sevilla y su gran estrategia consistente en dominar Tortosa, Denia y Valencia — posteriormente - parecen evidencias por mantener el abastecimiento de oro. Ahora bien, la emisión aurea de la taifa zaragozana también vio mermada su ley y calidad entrado el siglo XI, como demuestran los restos numismáticos o la incapacidad de pagar parias en oro y verse obligados a hacerlo en plata (Ariza Armada, 1995: 238) que sería, seguramente, vellón. La carencia de metales preciosos obligó a los poderes islámicos a fraccionar los dinares, incluso a acuñar en electro - mezcla de oro y plata-, como por ejemplo en Toledo o Valencia, como luego veremos. ${ }^{31}$

Sin embargo, a pesar del decrecimiento, buena parte de la geopolítica de esta centuria se va a fundamentar en la obtención de oro, como demuestra la entrada de los poderes cristianos en la carrera por obtenerlo, sea a través del comercio o de las parias. En el caso catalán la circulación de numerario andalusí se documenta ya desde 970. A partir 1018 Barcelona acuñó mancusos (Bonassie, 1987: 163.168), lo que nos está indicando que la materia prima debió importarse en forma de pesas o lingotes — mizcales_-, sin descartar que parte de la moneda barcelonesa tuviera su origen en la reacuñación de nume-

31 Se observa cómo en las parias que fueron exigidas existió una supervisión sobre la pureza del oro: [...] et hoc est mancusos CC de auro mundo; et alio mense de parias que accepit de Lerida et inconuentum est ei ad dare omnique tempore, et sunt mancusos centum de auro mundo [...], dice una conveniencia entre Ermengol III y Arnau Mir de Tost, CDSPAI, doc. 39, [1058.VIII.10]. La designación de auro mundo nos está indicando que el primero prometió al segundo oro de pureza, lo que señala la existencia de sospechas en la calidad del oro a consecuencia de la caída progresiva de su ley. Las referencias al tipo de oro son muy abundantes: [...] quinquaginta libras auri purissimi choquatur ex solbere [...], CSJPII, doc. 104, [1054.V.26]; [...] sed componam aut componat vobis in vinculum centum uncias auri puri $[. .$.$] , TDVB, doc. 55, [1041.XI.24]; [...] id est auri purissimi, in vinculo [...], TDVB, doc. 83,$ [1055.III.17]. Durante las décadas centrales de siglo XI la documentación comienza a mostrar adjetivos del oro que señalan su calidad. 
rario andalusí. Su entrada tuvo que ser por vía del comercio o como producto de acciones militares, fuesen contractuales o coercitivas. En el caso aragonés, Utrilla ya especifica que en la primera mitad del siglo XI las monedas que circularon eran hispanomusulmanas (Utrilla Utrilla, 2006: 545). A partir de la segunda mitad de la centuria, el crecimiento económico del reino de Aragón parece evidente (Utrilla Utrilla, 1995) y fue cuando tuvieron lugar las primera acuñaciones ${ }^{32} \mathrm{y}$ la documentación muestra más profusamente la existencia de bienes en metales preciosos no amonedados.

Es seguramente la historia de las guerras cidianas la más aireada en la tradición historiográfica de la Plena Edad Media española. La amplia bibliografía que se ha dedicado al tema relata con enfoques diferenciados los acontecimientos ocurridos desde la década de los 70 del siglo XI hasta la conquista de Valencia por los almorávides en 1102, donde la figura de Rodrigo Díaz alcanzó perfiles «hagiográficos» (Guichard, 2001: 49). Por el camino quedaron los denominados primer y segundo sitio de Valencia — habiendo sufrido, a la sazón, muchos- - y la capitulación de la ciudad en junio de 1094. Pero de toda la densa bibliografía al respecto, citada y por citar, no se ha tratado con profundidad un aspecto que nos parece de capital importancia para la geoestrategia: el oro de Valencia. Bonnassie afirmó que esta ciudad se había convertido en la llave de las rutas del oro (Bonnassie, 1987: 429), motivo por el cual su interés geopolítico habría sido capital desde el último tercio del siglo XI. La historiografía, en general, ha sido parca al respecto, quizá porque las fuentes disponibles no permiten profundizar en el asunto.

Con todo, existen demasiados indicios de que la ciudad del Turia ejerció una influencia geopolítica muy significativa. Prácticamente todos los príncipes más poderosos de la Península de ese momento, tanto cristianos como musulmanes, mostraron interés por poseerla, a excepción quizá de los abadíes sevillanos que tenían el interés puesto en otros puntos del Levante. ¿Nos están sugiriendo sus monedas de aceptable ley - a causa del acceso a las rutas de oro por el sur- el desinterés por entrar en la batalla geopolítica por el control del segundo punto de entrada del metal precioso? En medio de este avispero político, entre 1065 y 1102 Valencia fue asediada, desgastada, cercada u ocupada política o militarmente en múltiples ocasiones; constituyó, por antonomasia, el principal foco de interés geopolítico peninsular.

32 [... sic donent ad Sanctum Petrum Rome XVII uncias de auro de Iacca, dice el testamento de Valencia, la viuda de Ramón V de Pallars. PACBII, doc. 398, [1098-1100.II.19]. 
Podemos argüir que la carencia de gobiernos musulmanes fuertes y su dependencia efímera de Toledo primero y Castilla después pudieron favorecer desde inicios de los ochenta del siglo XI el interés por controlar una gran ciudad con salida al mar. Pero las fuentes ofrecen más indicios que respaldarían el interés por un oro con apellido valenciano, sin menoscabo de que estos y otros pretextos también influyeran. Hasta mediados de siglo, en la documentación catalana los pactos feudales o transacciones muestran el oro andalusí como elemento de cambio o valor. Las primeras acuñaciones de oro barcelonés aparecieron en el primer tercio de siglo, de mano del encargado del tesoro de la condesa Ermessenda $^{33}$ y probablemente a imitación de las acuñaciones hamudíes (Ibrahim, 1988: 265-266). Durante todos los años centrales y hasta el último cuarto de siglo aproximadamente la monete que hodie currit Barchinonam fue la referencia de cambio de la economía barcelonesa, que también estuvo vigente en el resto de condados. ${ }^{34}$ Sin embargo, el panorama cambió a partir de la década de los sesenta. Desde entonces las menciones al oro de Valencia se hacen mucho más frecuentes. ${ }^{35}$ Posteriormente, desde los ochenta, estas fueron constantes y ubicuas sobre todo en la documentación barcelonesa: [...] ex auro bono de Valencia ${ }^{36}[\ldots]$ mancusos XX de auro monete Valencia, ${ }^{37}[\ldots]$ donacionem mancusos $X$ auri rroals de Valencia, ${ }^{38}[\ldots]$ datos X milia solidos ad valentem de auro de Valencia legitimo tamen $[\ldots],{ }^{39}[\ldots]$ nummos quinque auri Valencie monete $[\ldots]{ }^{40}[\ldots]$ manccusus XII de auro de Valencia, qui est churibile in Barchinona ${ }^{41}$ Desde tal fecha hasta finales de siglo todo oro barcelonés pactado, hablado o mentado procedía de allí. Durante veinte años el oro de Valencia fue el elemento de más alto intercambio y pacto en la documentación catalana hasta que, a principios del siglo XII, con la conquista de esta ciudad por los almorávides, los morabatinos desbancaron a la moneda valenciana y a la designación generaliza-

$33[. .$.$] habeas super me ut ego reddam tibi mancusos VIII de auro de Bonoomine, hebreo. PACBI, doc.$ 18, [1027.VII.9].

34 Como en la documentación urgelitana, en la que comparte protagonismo en mayor proporción con la auri de Pontes monete, CDSPAI, doc. 103, [1073.IV.15], aludiendo a su lugar de acuñación.

35 Et istos mille mancosos sunt de auro de Valentia sine engan, dicen las primeras referencias en la documentación de los condes barceloneses: PACBI, doc. 39, [1038-1065]; [...] CC mancones auri cogti Valentie, PACBI, doc. 75, [1077.VII.13]; o [...] censum per quinquenium X solidos aureos Valencie, las similares en la documentación de Sant Pere d'Ager: CDSPAI, doc. 85, [1068.IV.4].

36 PACBI, doc. 139, [1083.I.31]

37 PACBI, doc 172, [1086.V.4].

38 TDVB, doc. 145c, [1087.VII.28]

39 PACBI, doc. 196, [1088.V.12].

40 CDSPAI, doc. 142, [1088.XII.20].

41 CDSPAI, doc. 231, [1090.VI.24-1091.VI.23]. 
da para referirse a este metal precioso. Veinte años a través de los cuales, precisamente, discurren las guerras cidianas y el avispero levantino, convirtiendo a la urbe en el objetivo geopolítico principal de la Península.

¿Tenía Valencia la capacidad de producir o importar este metal precioso en gran cantidad? Si analizamos las monedas emitidas en el siglo XI por esta taifa, nos encontramos información dispar. De las primeras que tenemos constancia son los dírhems de Mubarak y Muzaffar (1011-1020), con un alto contenido en plata. No se conocen monedas áureas de este periodo. Desde 1043-1044, 'Abd al-'Aziz (1021-1061) acuñó dírhems y dinares. Estos últimos, en fracciones, el principal indicio de la carencia de oro y que también evidenciaron las otras taifas. Sus dírhems presentan una plata de muy baja ley, llegando incluso a acuñar en cobre. Abd al-Málik (1061-1064) batió también fracciones de dinar, pero de electro, y con bajo contenido de plata. Durante la dependencia de la taifa de Toledo se acuñaron dinares de electro pero también de oro, aunque de baja ley. Las acuñaciones posteriores de al-Qádir presentan mayor peso, pero muestran los mismos patrones: dinares de oro de baja ley y de electro (García Lerga y Ruiz Sánchez, 2003: 93-124).

La dinámica de amonedación de Valencia, como vemos, se muestra similar a la del resto de taifas, repitiendo pautas de acuñación caracterizadas por la escasez de plata - tras las primeras décadas de la centuria-y el fraccionamiento de los dinares. Hacia mitad de siglo se observa un repunte en el uso del oro, más acusado hacia el último cuarto, pero este oro siempre fue de baja ley. Por consiguiente, las características de la moneda valenciana en este periodo no parecen coincidir con el renombre de su metal. Esta popularidad tuvo que deberse a la capacidad de producirlo o de importarlo, y no tanto de acuñarlo. No conocemos yacimientos áureos en el Sarq al-Andalus, ni en periodo posterior ni en la actual Comunidad Valenciana. Esto no implica que no existieran, pero en caso afirmativo hubieron de tener la capacidad de producir de modo industrial, lo cual no parece plausible. Con todo, la geoestrategia se hubiera centrado en controlar los puntos de extracción y su industria en lugar de la propia ciudad. De modo que esta fama debió residir en la capacidad de importación dentro de sus muros: a través del mar.

Es muy probable que hacia la mitad del siglo XI Valencia fortaleciera su conexión con las rutas mediterráneas que transportaban este metal y que tenían a Sicilia y Túnez, por ejemplo, como puntos comerciales clave. Por alguna razón que desconocemos se habría erigido como la puerta de entrada del poco oro que pudo atraerse en ese periodo, considerando no obstante que Mur- 
cia acuñó más y de mayor calidad en Levante y que Almería se erigió como la verdadera entrada de oro a inicios del dominio almorávide, pues se tiene constancia de que acuñó masivamente. La introducción durante esta época de numerario de otros Estados islámicos, como el fatimí, ${ }^{42}$ podría estar indicándonos la entrada de oro desde el Mediterráneo. Casi todos los hallazgos de monedas fatimíes - las más numerosas tras las propias andalusíes - han tenido lugar en Levante. Se trata de tesoros cuantiosos y de buena ley, datados en esta época y anteriores (Doménech-Belda, 2002: 481-490). ${ }^{43}$ Sin duda otros puertos mediterráneos pudieron haber atraído este tráfico, pero no está claro que sus capacidades portuarias y comerciales, así como otras dinámicas que se nos escapan, pudieran igualar a las del puerto valenciano. ${ }^{44}$ Sin soslayar que el renombrado oro de Valencia pudiera aludir a un apelativo fundamentado en la costumbre, como un distintivo consuetudinario que no explica una realidad sino que reproduce un epíteto instalado en la tradición. Sin embargo, de ser así, su denominación no se habría detenido abruptamente tras la conquista almorávide y la irrupción de los morabetinos.

Interrogantes que todavía quedan en torno a la motivación geopolítica y geoestratégica más poderosa de este periodo, y que marcó el ritmo de los enfrentamientos y de la gran estrategia no solo del valle del Ebro y del Levante, sino de toda la Península.

\section{Sal y estrategia militar}

El otro gran recurso con importancia geoestratégica fue la sal. Es probable que el interés por hacerse con ella no se haya considerado como merece a la hora de analizar la estrategia en el valle del Ebro. La sal es un mineral con una importancia capital a lo largo de la historia en general y de la Edad Media en particular. Se puede afirmar que sostenía las economías preindustriales, pues

42 Fracciones y unidades de dinares de buena ley, en gran parte de los casos (Doménech-Belda, 2017: 199-232).

43 Resulta sintomática al respecto también la existencia de una acuñación única en Al-Ándalus que se da en este momento en la taifa de Valencia, que imita el estilo fatimí y oriental, lo que nos estaría indicando unas influencias a través de rutas marítimas de las que todavía nos queda mucho por conocer. Cf. García Lerga y Ruiz Sánchez, 2003: 104.

44 Es en este momento cuando se habría iniciado el declive naval y militar del puerto de Denia, cuyo poderío marinero fue una constante a lo largo del siglo XI (O’Donell y Duque de Estrada y Blanco Núñez, 2010: 428). 
era un conservante natural de los alimentos. La alimentación anual de las familias, villas, ciudades o ejércitos, el comercio marítimo y terrestre o el transporte de bienes de consumo dependían del uso corriente de este mineral. La sal ha sido objeto de transacción e intercambio y ha motivado guerras y crisis a lo largo de la historia.

En Cataluña es bien conocida la importancia de la sal procedente del señorío de los Cardona (Méniz Márques, 1987; Galera Pedrosa, 1996), que erigió a esta familia vizcondal como una de las más poderosas. Su pujanza económica se basaba en la exportación del mineral procedente de sus dominios (Gual Camarena, 1965; Malartic, 1983), en un territorio donde el control de este bien estratégico no estaba en manos del Estado condal, como demuestra ampliamente la documentación. ${ }^{45}$ La sal de Cardona, que no era la única que se producía en el territorio, ${ }^{46}$ se exportaba a través del puerto de Barcelona, rivalizando con los emporios salineros de Venecia o Génova.

En el ámbito navarroaragonés el planteamiento albergaba algunas diferencias. Los reyes de Aragón y Pamplona trataron de arrogarse en la medida de lo posible la jurisdicción sobre las salinas, consideradas en la práctica como una regalía. Pero esta propiedad no fue exclusiva de reyes, pues también la compartieron con otros poderes feudales (Lapeña Paúl, 1984: 155-174). A la muerte de Sancho III el Mayor, el joven reino de Aragón tuvo que depender de explotaciones salinas que no habían detenido su rendimiento desde el periodo anterior. El ámbito pamplonés gozaba en torno al año mil de buenos yacimientos, como los de Salinas de Oro ${ }^{47}$ o Ucar. ${ }^{48}$ Sin embargo, la documentación del

45 En la CDADC, la sal se muestra como elemento ubicuo en los pactos feudales, ventas, permutas y otras operaciones de los vizcondes de Cardona, que tienen en muchos casos a los propios condes de Barcelona como protagonistas.

46 La producción en Tortosa también fue importante, como demuestra la carta poblacional tras su conquista por Ramón Berenguer IV, en la que retiene la novena de la producción de estaño y sal: PACBIII, doc. 893, [1148.XII.31-1149.XII.30]; o la extracción del territorio de Tarragona, como indica la renovación de la donación de la ciudad que el arzobispo hace al propio conde en 1151, que incluye la producción salinera del mismo: PACBIII, doc. 941, [1151.VIII]. En la Catalunya interior existieron yacimientos desde antiguo que eran explotados, pero de entidad menor, como en Ausona - Sant Hipólit y Vassalonga-: DMII, doc. 6, [1114.V.6]; o en el Rosellón: DMII, doc. 13, [1136.III.9]. Documentos que demuestran que las salinas estaban en manos de la nobleza o de las órdenes militares.

47 Población relacionada en la Edad Media con Geniz — que es sita in Pampilona —, aunque no puede descartarse que en realidad estemos hablando de Salinas de Pamplona, junto a la ciudad. De su abundancia salinera la documentación muestra buenos ejemplos. Ya hacia 947 se registran donaciones en la propia explotación: Cartulario de Albelda, doc. 17, [947]; y a finales del siglo XI el monasterio de San Martín de Albelda declaraba allí la posesión de XII areas salinas, lo que nos da una idea de su capacidad productiva: Cartulario de Albelda, doc. 68, [1094-1108].

48 La conocemos por una donación de Sancho Ramírez, DCRSR, doc. 14. [1077]. 
periodo muestra una concentración de explotaciones en la zona de bisagra ubicada en las altas Cinco Villas y la Jacetania. En este territorio, en los siglos $\mathrm{X}$ y XI se explotaban yacimientos como los de Nuro y Obano, ${ }^{49}$ Salvatierra de Esca,${ }^{50}$ Escalete ${ }^{51}$ o Salinas de Jaca,${ }^{52}$ en la frontera entre los reinos de Pamplona y Aragón. Para la zona central y oriental del joven reino cristiano - Sobrarbe y Ribagorza - están bien documentadas las llamadas salinas continentales y fuentes saladas pirenaicas (Mata Perelló, 2009). Algunos de estos yacimientos occidentales, empero, quedaron en el limes entre los territorios de Ramiro I y García III de Pamplona una vez fueron repartidos los dominios de Sancho el Mayor a partir de 1035.

La gestión de este recurso en el llano presentaba otras características. Para el siglo XIII las principales explotaciones salineras en la actual provincia de Huesca y en la ribera del Ebro se situaban en los yacimientos ubicados en Remolinos, Bujaraloz, Sástago, Agón, Aguinaliu, Juseu, Calasanz o Peralta, entre otros (Arroyo Ilera, 1961: 254), a los que habría que añadir alguno más, como Naval. Constituyeron con toda seguridad los principales puntos de abastecimiento salino de los poderes islámicos en el propio valle y al norte del Ebro. ${ }^{53}$ De entre ellos, la documentación coetánea y posterior y la tradición etnológica nos obliga a destacar los tres núcleos más importantes del valle medio: el primero el entorno salinero de Calasanz y Peralta, ${ }^{54}$ el segundo el de Naval y su territorio, ${ }^{55}$ y el tercero el de los yacimientos de Torres de Berrellén y Remolinos, a ambos márgenes del Ebro. Tres espacios ricos, con gran tradi-

49 En 978 el rey de Pamplona Sancho Abarca confirmó al monasterio de Siresa el diezmo de la sal de Nuro y añadió el de Obano. Cartulario de Siresa, doc. 11. [978.II.15].

50 El pago anual mediante sal por parte del monasterio de Santa María de Fuenfría nos está indicando, seguramente, la existencia de un pozo salino en explotación: CSJPI, doc. 34, [1005.III.1].

51 Entre Riglos y Yeste. La documentación nos informa de un pozo con capacidad de extracción: CDRI, doc. 107, [1056]. El mismo documento en CSJPII, doc. 137, [1056].

52 Bien conocidas y ya documentadas en el siglo VI por una donación del rey Alarico: CSJPI, doc. 1, [570]. Debió tener no uno sino varios puntos de explotación, lo cual explica que en 1135 Ramiro II concediese unas salinas a Santa Cruz de la Serós en Serracastel, lugar sin localizar pero cuyo topónimo se conoce en una partida de esa misma localidad: CSCS, doc. 27, [1135.I] y DRII, doc. 52, [1135.I]. Unos años después, la documentación del monasterio vuelve a hablar de la extracción de sal, pero en este caso en la misma localidad de Salinas: CSCS, doc. 42, [1182.III].

53 A diferencia de la minería de metales, el Islam peninsular concebía la explotación salinífera de propiedad estatal pero la cedía contractualmente a particulares (Echevarría Arsuaga, 2010: 62).

54 Con yacimientos de pleno rendimiento en ambas localidades, además de Castillonroy, Aguinaliu, Juseu, Estopiñán, Caserras del Castillo y Gavasa, en la Sierra de la Carrodilla (Mata Perelló, 2011: 154; Castillón Cortada, 1985: 69-90).

55 Que incluiría otras salinas menores como El Grado, Salinas de Hoz, Castro, Secastilla o Puy de Cinca (Mara Perelló, 2011: 154). 
ción, que siendo los yacimientos de mayor calado del territorio tuvieron que abastecer de sal a las madinas y localidades islámicas del valle medio y el Segre. Tres espacios que, a la sazón, se convirtieron en tres de los puntos geoestratégicos más calientes de la expansión feudal aragonesa. ¿Casualidad?

El entorno salino de Calasanz fue objetivo militar durante cincuenta años. ${ }^{56}$ En 1048 Arnau Mir de Tost conquistaba Gabasa y trataba de asediar Calasanz. La primera, enclavada en un barranco, carece de valor militar o visual. En 1057 cercó Caserres del Castillo, y seis años más tarde, en 1063 y junto a Ramón Berenguer I, conquistó la mitad del núcleo salinero: Pilzán, Purroy y Estopiñán, fortificando una bolsa estratégica en la línea natural de expansión aragonesa y urgelitana. Las tentativas contra Calasanz siguieron, a pesar de controlar ya el acceso a Balaguer o a Tamarite con las plazas de alrededor: en 1090 la conquistó Ermengol IV. ${ }^{57}$ Pero es Pedro I quien en 1098 la expugnó definitivamente. ${ }^{58}$ Consta en la documentación de este periodo su pleno rendimiento salinero. A buen seguro el factor estrictamente estratégico de este territorio fue un acicate, dado que estaba conformado por plazas a pie de sierra que controlaban una planicie de unos doce kilómetros al sur hasta San Esteban de Litera y Tamarite, todavía musulmanas entonces, y con visibilidad de Monzón y el Pueyo de Barbastro. Además, este territorio oriental de la Sierra de la Carrodilla, ubicado entre la alta Litera y la baja Ribagorza, constituye uno de los espacios mineros más ricos de Aragón y el más copioso en algunos minerales fundamentales de toda la actual provincia de Huesca. Estopiñán y Caserres son ricos en aerinita ${ }^{59}$, pero sobre todo destacan por su abundancia como ningún otro territorio en hematita, magnetita $u$ olivino ${ }^{60}$. Los dos primeros

56 Ya anteriormente el hisn de Calasanz está bien documentado en varias ocasiones, junto al de Mamaqastra, justo al lado, ambos pertenecientes al distrito de Lérida, lo que nos indica la importancia estratégica de este enclave: Al-Udri, p. 41.

57 En enero de ese año pactó previamente su conquista con Ramón V de Pallars Jussà, con la intención de atacar también San Esteban y Tamarite: PACBI, doc. 219, [1090.I].

58 En 1195 la plaza figura como tenencia de Fortún Dat, lo que ha generado confusión. Laliena ha considerado que el asedio de Pedro I estaría motivado por una rebelión (Laliena Corbera, 1996: 185-186). En 1150 la esposa de un dirigente andalusí entregó a San Pedro de Ager tres salinas y dos eras en Calasanz, por lo que la suposición de Laliena podría probarse con el hecho de que señores locales hubieran rendido o pacificado la plaza cincuenta años antes a cambio de prebendas: CDSPAII, doc. 302, [1150.XII.25].

59 Mineral del que se extrae el color azul de las pinturas al fresco. De hecho, el Pantocrator de Sant Climent de Tahull está pintado con este elemento en sus coloraciones azules. De igual modo los frescos del Monasterio de Sijena que se conservan en el MNAC están pintados con este pigmento.

60 Este mineral se usa para purificar el hierro. Además, la gran concentración también de manganeso —en forma de pirolusita y otros - hace de las vetas de óxido de hierro ricas en este elemento, lo que otorga al metal una gran calidad. 
minerales constituyen la veta más común de óxido de hierro, que es la materia prima de la que se extrae este metal. Por consiguiente, nos encontramos ante un territorio de gran valor geoestratégico. ${ }^{61}$

Sabemos por un documento de Jaime I de 1274 de la concesión a las salinas de Naval del monopolio de venta de un «territorio que abarcaba desde Monegros a Canfranc» (Conte Cazcarro, 2013: 96). Al margen de consideraciones útiles para la época en que el documento fue producido, en lo que a nosotros concierne nos está informando de la capacidad descomunal de abastecimiento de esta explotación; a la sazón, era la cabeza de un territorio salinífero de primera magnitud. ${ }^{62}$ Por la documentación del periodo sabemos que esta plaza tenía almunias y localidades dependientes ${ }^{63}$ y que los yacimientos menores de su periferia funcionaban en el momento de la conquista cristiana. ${ }^{64}$ De nuevo nos encontramos ante un espacio a pie de sierra, adyacente al Cinca y que se caracteriza también por el interés en recobrarlo por parte del poder islámico una vez se ha ocupado. No tenemos noticias de que fuera conquistada por la fuerza las dos veces que fue tomada, lo que no quiere decir que no existiera un asalto en la primera de sus conquistas. Esto debió suceder allá por 1084, con un cerco previo a Secastilla, que también poseía salinas. Posteriormente fue recobrada por al-Musta'in II — seguramente a finales de $1092 \mathrm{o}$ en 1093 - y fue en 1095 cuando Pedro I la ocupó definitivamente a través de un pacto con los barones locales. Sin duda, esta élite no solo detentaba la explotación de las salinas ${ }^{65}$ sino también la capacidad autónoma de negociación.

El caso más paradigmático es el tercero. En 1091 Sancho Ramírez instaló una plaza fortificada poniendo en práctica un tipo de operación militar deno-

61 Cabría no eludir la existencia de un tercer factor, el de constituir ruta de paso tradicional entre el reino de Aragón y los condados catalanes hasta finales del siglo XI. En 1127, Alfonso I y Ramón Berenguer IV se reunieron en Calasanz — quando rex fuit ad iuncta de comte de Barcalona, Cartas poblaciones, doc. 41, [1127] —, lo que podría indicarnos un potencial punto intermedio territorial con tradición itineraria.

62 Cuyo suministro entró en conflicto en la Baja Edad Media con los derechos del monasterio de San Juan de la Peña (Lapeña Paúl, 1984: 164-165).

63 Se evidencia en la donación efectuada tras su primera ocupación: DCRSR, doc. 19, [1082].

64 En 1110 la condesa Beatriz añadió a una donación en territorio de Castro: illud sal de illa salina qualem partem ego impetravi ibi a rege Sancio, DECCRI, doc. 153, [1110.XI.24]; esto concordaría con la explotación existente en ese mismo término localizada en Mata Perelló cerca de Naval (Mata Perelló, 2011: 154).

65 En 1135 Ramiro II otorgó las salinas del Lopillo moro et de suos filios a dos seniores, DRII, doc. 68, [1135.VI]. Ubieto juzga el documento como falsificado, pero su validez jurídica no exime de tomarlo en consideración por la información que aporta acerca de la propiedad salinífera. 
minada dislocación estratégica, en medio de territorio enemigo para controlar Zaragoza. Tradicionalmente se ha considerado al castillo «Super Caesaraugusta» de El Castellar como un verdadero puesto avanzado con el que «fomentar la inseguridad entre los musulmanes de los valles del Gállego y el Jalón» (Laliena Corbera, 1996: 142). La existencia en la documentación de una antigua paria y de una nueva paria significaría la consecuencia de la amenaza de este castillo de aproximación. Ahora bien, es necesario plantear de nuevo si el interés de este enclave fue estrictamente militar o también económico.

El Castellar se enseñorea eficazmente del espacio con la mayor capacidad de producción salinera del Ebro, ${ }^{66}$ culminando un reguero de saladares que se prolongaban desde Valtierra hasta el Gállego (Arroyo Ilera, 1961: 255). En la margen izquierda, las salinas de Remolinos documentan un valor de 8.000 sueldos en $1269 ;{ }^{67} \mathrm{y}$ las de la margen derecha se extendían desde illa alhandeca de Pola usque ad terminum de Alhozean. ${ }^{68}$ Un territorio salinífero de unos 25 kilómetros de amplitud, con yacimientos en pleno rendimiento ${ }^{69}$ a uno y otro lado del cauce y que abarcaría, de este a oeste, Remolinos, Pola - atalaya desaparecida, hoy una partida de Torres de Berrellén—, Santa Inés, El Castellar, El Molino, Sobradiel y Alfocea (Gascón Ricao, 2007), todos ellos puntos a su vez fortificados — hisn o almenaras - . «Super Caesaraugusta» se sitúa en el centro de esta línea de extracción salinífera fortificada, en la desembocadura del Jalón y controlando un espacio con yacimientos conectados por barcas, con capacidad para vigilar y preparar una defensa y seguramente con apeaderos fluviales a orilla contraria del enemigo. ${ }^{70} \mathrm{~A}$ tenor de la amplitud del yacimiento y la distancia con Zaragoza, era seguramente el principal foco de abastecimiento de sal de la ciudad. Por consiguiente, lo más seguro es que el valor estratégico de «Super Caesaraugusta» trascendiera lo meramente militar para abarcar el del control de los recursos, privando de sal a la madina o entorpeciendo un abaste-

66 Al-Razi da cuenta de su «sal blanca e muy luziente» (Malpica Cuello, 2005: 261). Del mismo tenor hablan Al-Himyari, especificando que su sal gema es de una calidad superior: RM, pp. 119-120; y AlUdri, p. 12, que afirma que es sal blanca, sin impurezas y lisa.

67 Datos computados a partir de la renta local, que no deben tomarse como absolutos dado que «no siempre se indica en concreto el valor, sino que va mezclado con la renta de una pequeña villa [...]» (Arroyo Ilera, 1961, 257).

68 Según los fueros a los pobladores de El Castellar, Cartas de población, doc. 8 [1091].

69 La propia carta de población de El Castellar lo especifica, así como la documentación posterior: Alfonso II le confirma en 1177 illas salinas de Pola al monasterio de Veruela: DMSMV, doc. 118, [1177. VI]. En el mismo documento de donación de la iglesia del castillo al obispo de Pamplona dice: Damus etiam portu et salinas. CDSR, doc. 125, [1091.VIII].

70 CDSR, doc. 125, [1091.VIII]. 
cimiento de vital importancia. No es casualidad, pues, que los mayores puntos de fricción estratégica durante la reconquista aragonesa comprendieran las explotaciones más importantes de sal en el cauce y al norte del Ebro. ${ }^{71}$

\section{Conclusiones e inercias}

Si analizamos desde una perspectiva genuinamente militar los hechos bélicos del pasado observamos que detrás de cada planificación siempre existe un interés geoestratégico vinculado al control o privación de recursos económicos del adversario. Esta perspectiva militar permite trascender la concatenación de acontecimientos políticos y bélicos sin interpretación para dotarlos de argumentos estratégicos, tomando incluso modelos anteriores. La motivación por el control de la sal o de los metales preciosos - entre otros recursos- estuvo presente en las decisiones estratégicas, y eso es lo que hemos tratado de interrelacionar en este artículo, como síntesis de un proyecto de investigación de mayor calado en el que nos vemos inmersos en este momento.

Sobre la expansión feudal en el valle del Ebro se ha escrito e historiado en las últimas décadas lo necesario. La jugosidad de las fuentes, como todo el mundo ya conoce, no se compara con las bajomedievales o modernas. Su finitud, por tanto, nos obliga a condicionar un relato que corre el riesgo de concebirse como un arma de doble filo: por un lado, insta al historiador del periodo alto y pleno medieval a amojonar un redil discursivo cuyos trazos más gruesos - y por tanto más visibles - son la historia del propio poder y las instituciones, vedando elementos tan en boga en los últimos años como la historia social o la historia económica. Aparentemente, sin solución de continuidad. Por otro, esta finitud tiende a agotar el armazón reflexivo, cuando precisamente el campo considerable de lo desconocido debiera constituir acicate con el que plantear nuevos espacios de reflexión o lecturas auxiliares de tales fuentes.

71 Y seguramente no son los únicos. El alto valor estratégico de plazas como Agüero no debió circunscribirse solo a ser un enclave a pie de sierra, bien situado y con buen control visual hacia el sur. Se trató también del baluarte de acceso a la riqueza salinífera del reino, pues protegía Salinas de Jaca y Escalete, yacimientos que se sitúan a unos pocos kilómetros al norte. Su conquista y reconquista, nuevamente, se documenta en varias ocasiones. Como tampoco debemos desestimar el control de la sal como factor condicionante en la planificación de la conquista del Sistema Ibérico por parte de Alfonso I. En torno a la importante plaza de Molina de Aragón se extiende una de las concentraciones saliníferas más importantes de la Península, ya en activo en época islámica, con yacimientos como los de Valdeguilla, Saelices de la Sal, Almalla, Terzaga o Traid (Terán Manrique, 2017: 271-278; Ortego Rico, 2013: 210-211). 
Considero con firmeza que a veces se nos olvida que la expansión feudal en el valle del Ebro desde la segunda mitad del siglo XI fue una guerra. Y como tal, de igual modo a como sucedía y había sucedido en otros periodos a lo largo y ancho del orbe, retuvo condicionantes basales propios del genio militar necesario para alcanzar los objetivos que una guerra motiva, sean ideológicos, espirituales, de poder, de ascenso social o de riqueza; tantos de los cuales han sido desarrollados ya. Por tanto, se hace necesario acercarnos a esos aspectos más próximos al propio hecho militar para recluir y analizar - en la medida de lo posible - cada acción expansiva y dotarla de sentido. Me refiero a su contexto inmediato. En este artículo hemos desarrollado unas reflexiones de tipo general sobre dos de los recursos económicos más importantes de la Edad Media: el oro y la sal. Y lo hemos hecho no tanto como elementos coadyuvantes en la construcción del relato económico o de poder del periodo como en su importancia geoestratégica - y por tanto bélica — inmediata: la perentoria necesidad de poseerlos para bien propio en el transcurso de una guerra, o, y casi más importante aún, la improrrogable obligación de privar de ellos al enemigo. El oro y la sal son los más importantes, pero en futuras reflexiones, y echando mano de otras disciplinas - con las que al historiador tradicional le cuesta tanto pertrecharse-, no deberíamos obviar la importancia geoestratégica de controlar las vetas de hierro, ${ }^{72}$ el carbón, los recursos madereros, el agua, el estaño, minerales diversos, etcétera, como fundamento menos idealista -0 idealizado - del secular devenir del hombre.

Ahora bien. Es de justicia acotar que en modo alguno estamos de acuerdo con la premisa de que los señores feudales ampararan todas sus motivaciones de conquista en pretextos económicos o pragmáticos. No piense el lector que todas las reflexiones desarrolladas aquí pretenden invalidar el relato de la conquista del valle que se ha construido desde los años cincuenta del siglo XX. En absoluto. Las motivaciones económicas, desde un prisma estrictamente estratégico, fueron a nuestro juicio solo un condimento necesario en la planificación militar, insertado como un componente más dentro de las dinámicas feudales, ideológicas y políticas que motivaron la conquista del valle. Pero ello no es óbice para que admitamos que en un plano ejecutivo la fijación de objetivos militares tuvo que ampararse en criterios operacionales, aunque a la postre el resultado final diera en la aprehensión total del territorio y su inserción

72 Junto al manganeso, cuyas vetas conjuntas dotaban al primero de una calidad natural próxima a la del acero. 
en las dinámicas feudales de los estados. No obstante, en el transcurso de la guerra, y desquitados de conocer el resultado final con el que reflexionamos hoy, el encaje de decisiones y acciones militares ordinarias respondía en tiempo real, obviamente, a intereses y objetivos amparados en la materialidad. $\mathrm{O}$ lo que es lo mismo, en el campo del estratega.

\section{Referencias}

\subsection{Fuentes documentales (según su citación abreviada)}

Ad-Tadkira (Kitab al-Tadkira al-Harawiyya fi l-hiyal al-harbiyya, de 'Ali b. Abi Bakr al-Harawi)

SOURDEL-THOMINE, Janine, ed. (1961-1962), «Les conseils du Sayh al-Harawi a un prince ayyubide», Bulletin d'etudes orientales, 17: 205-268.

Al-Bayan I (Al-Bayan al-Mugrib, Ibn 'Idari)

Maíllo Salgado, Felipe, ed. (1993), La caída del Califato de Córdoba y los Reyes de Taifas. Salamanca, Universidad de Salamanca.

Al-Bayan III (Al-Bayan al-Mugrib, Ibn 'Idari)

Huici MirandA, Antonio, ed. (1963), Ibn 'Idari. Al-Bayan al-Mugrib. Nuevos fragmentos almorávides y almohades. Valencia, Anubar.

Al-Hulal (Al-Hulal al Mawsiyya)

Huici MiRAnda, Antonio, ed. (1951), Al-Hulal al Mawsiyya. Crónica árabe de las dinastías almorávide, almohade y benimerín. Tetuán, Editora Marroquí.

Al-Muqtabis V (Al-Muqtabis fi tarij al-Andalus V, Abu Marwán Hayyán Ibn Jálaf Ibn Husáin Ibn Hayyán al-Qurtubi)

Viguera Molins, Ma Jesús y Corriente, Federico, eds. (1981), Crónica del califa 'Abdarrahman III an-Nasir entre los años 912 y 942 (al-Muqtabis V). Zaragoza, Anubar.

Al-Udri (Tarsi al-ajbar, Áhmad ibn Úmar ibn Anas al-'Udri)

De la Granja, Fernando, ed. (1966), La Marca Superior en la obra de al-'Udri. Zaragoza, CSIC.

CART (Crónica anónima de los Reyes de Taifas)

Salgado Maillo, Felipe, ed. (1991), Crónica anónima de los Reyes de Taifas. Madrid, Akal.

Cartas poblaciones (Cartas de población del reino de Aragón en los siglos medievales)

Ledesma Rubio, María Luisa, ed. (1991), Cartas de población del reino de Aragón en los siglos medievales. Zaragoza, Institución Fernando El Católico.

Cartulario de Albelda (Cartulario del Monasterio de San Martín del Albelda) Ubieto ARTETA, Antonio, ed. (1981), Cartulario de Albelda. Zaragoza, Anubar. 
Cartulario de Siresa (Cartulario del Monasterio de San Pedro de Siresa) UbIETO ARTETA, Antonio, ed. (1986), Cartulario de Siresa . Zaragoza, Anubar.

CDADC (Colección diplomática archivo ducal de Cardona) RODRIGueZ BERnAL, Francesc (ed.) (2016), Col-lecció diplomàtica de l'Archivo Ducal de Cardona (965-1230), Barcelona, Fundació Noguera.

CDAI (Colección diplomática de Alfonso I) LeMA Pueyo, José Ángel, ed. (1990), Colección diplomática de Alfonso I de Aragón y Pamplona (1104-1134). San Sebastián, Eusko Ikaskuntza.

CDPI (Colección diplomática de Pedro I)

Ubieto ArtetA, Antonio ed. (1951), Colección diplomática de Pedro I de Aragón y Navarra. Zaragoza, CSIC.

CDRI (Colección diplomática de Ramiro I)

VIRUETE ERDOZAÍn, Roberto, ed.(2013), La colección diplomática del reinado de Ramiro I de Aragón (1035-1064). Zaragoza, Institución Fernando el Católico.

CSJPI (Cartulario del Monasterio de San Juan de la Peña, vol. I.)

Ubieto ArTetA, Antonio, ed. (1962), Cartulario de San Juan de la Peña I. Valencia, Anubar.

CSJPII (Cartulario del Monasterio de San Juan de la Peña, vol. II)

Ubieto Arteta, Antonio, ed., (1963), Cartulario de San Juan de la Peña. II. Valencia, Anubar.

CDSPAI (Colección diplomática de San Pedro de Ager. Vol. II)

CHESÉ LAPEÑA, Ramón, ed. (2011), Col·leccio' diplomàtica de Sant Pere d'Àger fins 1198. Vol. I. Barcelona, Fundació Noguera.

CDSPAII (Colección diplomática de San Pedro de Ager. Vol. II)

CHESÉ LAPEÑA, Ramón, ed. (2011), Col·leccio' diplomàtica de Sant Pere d'Àger fins 1198. Vol. II. Barcelona, Fundació Noguera.

CDSR (Colección diplomática de Sancho Ramírez)

CANELlAs LóPEZ, Ángel, ed. (1993), La colección diplomática de Sancho Ramírez. Zaragoza, Real Sociedad Económica Aragonesa de Amigos del País.

CEP (Crónica de los estados peninsulares)

UbIETO ARTETA, Antonio, ed. (1955), Crónica de los estados peninsulares: texto del siglo XIV. Granada, Universidad de Granada.

CSCS (Cartulario de Santa Cruz de la Serós)

Ubieto Arteta, Antonio, ed. (1966), Cartulario de Santa Cruz de la Serós. Valencia, Anubar.

DAII (Documentos de Alfonso II)

SÁnchez CASAbón, Ana Isabel, ed. (1995), Alfonso II Rey de Aragón, Conde de Barcelona y Marqués de Provenza. Documentos (1162-1196). Zaragoza, Institución Fernando el Católico.

DCRSR (Documentos correspondientes al reinado de Sancho Ramírez)

SAlarRullana DE Dios, José, ed. (1907), Documentos correspondientes al rei- 
nado de Sancho Ramirez: desde TXXIII hasta TLXXXXIIII años: documentos reales procedentes de la Real Casa y monasterio de San Juan de la Peña. Vol. 1. Zaragoza, M. Escar Tip.

De Re Militari (Epitome de Re Militari, Flavio Vegecio Renato)

Paniagua Aguilar, David, ed. (2015), Compendio de técnica militar. Madrid, Cátedra.

DECCRI (Documentación episcopal y del cabildo catedralicio de Roda de Isábena) GRAU QUIROGA, Nuria, ed. (2010), Roda de Isábena en los siglos XI-XIII. La documentación episcopal y del cabildo catedralicio. Zaragoza, Institución Fernando el Católico.

DMII (Diplomatari del Masdéu. Vol. II)

TrETON, Rodrigue, ed. (2010), Diplomatari del Masdéu. Vol. II. Barcelona, Fundació Noguera.

DMSMV (Documentos del Monasterio de Santa María de Veruela)

Cabanes PeCourt, María de los Desamparados, ed. (2017), Documentos del Monasterio de Santa María de Veruela (Zaragoza). I (1127-1239). Zaragoza, Institución Fernando el Católico.

DRII (Documentos de Ramiro II)

UbIETo ARTETA, Antonio, ed. (1988), Documentos de Ramiro II de Aragón. Zaragoza, Anubar.

Ibn Hudayl I (Kitab tuhfat al-anfus wa-si'ar sukkan al-Andalus, Abu-l-Hàssan Alí ibn Abd-ar-Rahman al-Fazarí al-Andalussí)

MERCIER, Louis, ed. (1939), 'Aly ben 'Abderrahman ben Hodel el Andalusy. L'ornement des ames et la devise des habitants d'El Andalus. Paris, Librairie Orientaliste Paul Geuthner.

Kekaumenos (Strategikon, Kekaumenos)

Cecaumeno, Consejos de un aristócrata bizantino. Traducción de Juan Signes Codoñer. Madrid, Alianza, 2000.

PACBI (Pergaminos del Archivo condal Barcelona. Vol. I)

Baiges Jardí, J. Ignasi, Gaspar Feliú MonTfort y Josep María SAlRaCH MARÉS, eds. (2010), Els pergamins de l'Arxiu Comtal de Barcelona, de Ramon Berenguer II a Ramon Berenguer IV. Vol. I. Barcelona, Fundació Noguera.

PACBII (Pergaminos del Archivo condal Barcelona. Vol. II)

Baiges Jardí, J. Ignasi, Gaspar Feliú MonTfort y Josep María SAlRaCH MARÉS, eds. (2010), Els pergamins de l'Arxiu Comtal de Barcelona, de Ramon Berenguer II a Ramon Berenguer IV. Vol. II. Barcelona, Fundació Noguera.

PACBIII (Pergaminos del Archivo condal Barcelona. Vol. III)

BAiges Jardí, J. Ignasi, Gaspar Feliú MonTfort y Josep María SAlRaCH MARÉS, eds. (2010), Els pergamins de l'Arxiu Comtal de Barcelona, de Ramon Berenguer II a Ramon Berenguer IV. Vol. III. Barcelona, Fundació Noguera.

RM (Kitab ar Rawd al-mitar fi Habar al Aktar, Muhammad bin Abd al-Munim alHimyari) 
Levi ProvençAL, Evariste (1938), La Penínsule Ibérique au Moyen-Age d'apres le Kitab ar Rawd al-mitar fi Habar al Aktar. Leiden, E. J. Brill.

Stratagemata (Stratagemata, Traducción del siglo XV, Frontino)

RocA BAREA, María Elvira, ed. (2010), Tratado militar de Frontino. Humanismo

y caballería en el Cuatrocientos castellano. Traducción del siglo XV. Madrid, CSIC.

Strategikon (Strategikon, Mauricio, emperador de Oriente)

MAgaña Orúe, Emilio, Julio RodríGueZ GonzÁleZ y José Ignacio DE LA TORRE RODRÍGUEZ, eds. (2014), Strategikon (sobre el general). Madrid, Ministerio de Defensa.

Taktika (Taktika, Leon VI)

DENNIS, George, ed. (2010), The Tactica of Leo VI. Washington D.C., Dumbarton Oaks.

TDVB (Textos y documentos de los vizcondes de Barcelona)

RUIZ-DOMÉNEC, José Enrique, ed. (2006), Quan els vescomtes de Barcelona eren Història, crònica i documents d'una família catalana dels segles X, XI i XII. Barcelona, Fundació Noguera.

\subsection{Referencias bibliográficas}

ANDRESKI, Stanislav (1968), Military organization and society. London, Routledge \& Kegan Paul Ltd.

ARIZA ARMADA, Almudena (1995), «Monedas en los reinos de taifas.» En V Semana de estudios medievales: Nájera, 1 al 15 de agosto de 1994. Logroño, Instituto de Estudios Riojanos: 233-240.

ARROYO ILERA, Rafael (1961), «La sal en Aragón y Valencia durante el reinado de Jaime I», Saitabi, 11: 253-261.

Asín PALACiOS, Miguel (1934), «Un códice inexplorado del cordobés Ibn Hazm», Al-Andalus, 2/1: 1-56.

BOLÍVAR OCAMPO, Alberto (2012). «La importancia de la geopolítica y geoestrategia en los planes de desarrollo», Military Review, marzo-abril 2012: 25-33.

BonnAssie, Pierre (1987), Cataluña mil años atrás (Siglos X-XI). Barcelona, Península.

CElELIER, Pierre (1979), Geopolítica y geoestrategia. Buenos Aires, Pleamar.

CANTÓ GARCíA, Alberto, Patrice CRESSIER y Paula GrañEdA MiÑón, eds. (2008), Minas y metalurgia en al-Ándalus y Magreb occidental. Explotación y poblamiento. Madrid, Casa de Velázquez.

CAstillón CORTADA, Francisco (1985), «Las salinas de Aguinaliu, Calasanz, Juseu y Peralta (Huesca)», Argensola, 99: 69-90.

CASTRO HernándeZ, Pablo (2015), «La naturaleza y el mundo en la Edad Media: perspectivas teológicas, cosmológicas y maravillosas. Una revisión conceptual e historiográfica» Historias del Orbis Terrarum, 10: 1-35. 
Conte CAZCARro, Anchel (2013). «Los moros de Naval (Nabal) en los siglos XV y XVI», Aragón en la Edad Media, 24: 91-139.

DE VILLAR IGLESIAS, José Luis (2017), Al-Ándalus y las fuentes del oro. [Tesis doctoral], Sevilla, Universidad de Sevilla.

DOMÉNECH-BELDA, Carolina (2002), «El Numerario Fatimí en el Sarq Al-Andalus.» En Actas del X Congreso Nacional de Numismática (Albacete, 1998). Madrid, Museo Casa de la Moneda, 481-490.

DomÉnECH-BELDA, Carolina (2017) «Fatimíes y taifas: la moneda de oro fatimí en al-Andalus», Al-Qanțara, 37/2: 199-232.

Domerge, Claude (2008), «Conclusiones». En Alberto Cantó García, Patrice Cressier y Paula Grañeda Miñón (eds.), Minas y metalurgia en al-Ándalus y Magreb occidental. Explotación y poblamiento. Madrid, Casa de Velázquez: 251-252.

ECHEVARRÍA ARSUAGA, Ana María (2010), «Explotación y mano de obra en las minas y salinas de al-Andalus», Espacio Tiempo y Forma. Serie III, Historia Medieval, 23: 55-74.

FREEDMAN, Lawrence (2019), Estrategia. Una historia. Madrid, La Esfera de los libros.

FERREIRA PRIEGUE, Elisa (1994), «Saber viajar: arte y técnica del viaje en la Edad Media.» En IV Semana de Estudios Medievales: Nájera, 2 al 6 de agosto de 1993. Logroño, Instituto de Estudios Riojanos: 45-69.

GALERA PEDROSA, Andreu (1996), «La extracción de sal gema en el nordeste peninsular: las salinas de Cardona durante la Edad Media (siglos X-XIII)» En Actas de las I jornadas sobre minería y tecnología en la Edad Media peninsular. León, Fundación Hullera Vasco-Leonesa: 225-239.

GARCíA FITZ, Francisco (1998), Castilla y León frente al Islam. Estrategias de expansión y tácticas militares (siglos XI-XIII). Sevilla, Universidad de Sevilla.

GARCÍA LERGA, Rubén-Lot y Almudena RUIZ SÁNCHEZ (2003), «Las acuñaciones monetarias en la taifa de Valencia (s. XI)», ARSE, 37: 93-124.

GASCÓN RICAO, Antonio (2007), «El hechizo de El Castellar», Cuadernos de Aragón, 35: $11-115$.

GRAÑEDA MiÑón, Paula (2008), «La explotación andalusí de la plata en Córdoba.» En Alberto Cantó García, Patrice Cressier y Paula Grañeda Miñón, Minas y metalurgia en al-Ándalus y Magreb occidental. Explotación y poblamiento, Madrid, Casa de Velázquez, 19-36.

Gual Camarena, Miguel (1965), Para un mapa de la sal hispana en la Edad Media. Murcia, Universidad de Murcia.

GUICHARD, Pierre (2001), Al-Ándalus frente a la conquista cristiana, Valencia, Universitat de Vàlencia.

GUVEIRA MONTEIRO, Joao (2009), «Vegécio ea prática militar medieval: influência real e condicionalismos». Biblos. Revista da Faculdade de Letras (Universidade de Coimbra), VII: 68-118. 
IBRAHIM, Tawfiq B. Hafif (1990), «Consideraciones sobre el conflicto omeya-fatimí y las dos acuñaciones conocidas de al-Jair Ibn Muhammad ibn jazar al-Magrawi», Boletín de la Asociacion Española de Orientalistas, 26: 296-302.

IBRAHIM, Tawfiq B. Hafif (1998) «Nota sobre el posible origen del Mancuso de Bonnon». II Jarique de numismàtica hispano-àrab. Lérida, Institut d'Estudis Ilerdencs: 265-266.

IBRAHIM, Tawfiq B. Hafif y Sebastián GASPARIÑO (2016), «The Dirhams (and Dinars) issued during the Umayyad Emirate and Caliphate in Al-Andalus according to the index of Vives», Mancuso, 5: 17-28.

LALIENA CORBERA, Carlos. La formación del Estado feudal. Aragón y Navarra en la época de Pedro I. Huesca, Instituto de Estudios Altoaragoneses (Colección de Estudios Altoaragoneses, 42).

LAPEÑA PAÚL, Ana Isabel (1984), «San Juan de la Peña y la posesión y explotación de Salinas», Aragón en la Edad Media, 6: 155-174.

LEMA PUEYo, José Ángel (2008), Alfonso I el Batallador, rey de Aragón y Pamplona (1104-1134). Gijón, Trea.

MALARTIC, Yves (1983), «Le sel en Catalogne». En Les pays de la Méditérranée Occidentale au Moyen Âge. Études et recherches. (Actes du $106^{e}$ Congrès National des Sociétés Savantes, Perpignan, 1981). París, Comité des Travaux Historiques et Scientifiques (CTHS): 181-200.

MalpiCa Cuello, Antonio (2005), «La sal en al-Andalus. Poblamiento y explotación de los recursos salineros», I Seminário Internacional sobre o sal português. Porto, Instituto de História Moderna da Universidade do Porto, 257-277.

MATA-PERElló, Josep María (2009), «Datos para el conocimiento de las salinas continentales pirenaicas de Aragón (comarcas de la Litera, la Ribagorza, el Sobrarbe y el Somontano)» En La explotación histórica de la sal: investigación y puesta en valor. (I Congreso Internacional SEHA. Salinas de Espartinas, Ciempozuelos, 2009). Madrid, Sociedad Española de Historia de la Arqueología: 63-72.

Mata-Perelló, Josep María, Carolina Restrepo Martínez y Jaime Vilaltella FARRÀS (2011), «Las salinas continentales y las fuentes saladas pirenaicas de Aragón.» En Josep María Mata-Perelló, ed., Actas del Primer Congreso Internacional sobre Termalismo, Minería y Geología (Ariño, octubre del 2010). Andorra, Silvia de Cambra: 153-162.

MÉniz MÁrqueZ, Catalina (1987), «Vente et impôt du sel en Catalogne. Les salines de Cardone.» En Le roi, le marchand et le sel. (Actes de la table ronde "L'impôt du sel en Europe, XIII -XVIII ${ }^{e}$ siècle”, Saline royale d'Arc-en-Senans, 23-25 septembre 1986). Lille: Presse universitaries de Lille: 99-104.

MORILlO, Stephen (2002), «Battle Seeking: The Context and Limits of Vegetian Warfare», Journal of Medieval Military History, 1: 21-42.

O’DOnell y DuQue de EstradA, Hugo y José María Blanco NúÑEZ (2010), «Las marinas medievales y la guerra en el mar: medios, tácticas, acciones.» En Miguel 
Ángel Ladero Quesada, coord., Historia Militar de España. Edad Media. Madrid. Ministerio de Defensa.

ORTEgo Rico, Pablo (2013), «Las salinas de Atienza, Medinaceli y Molina de Aragón en la Baja Edad Media: propiedad, comercio y fiscalidad», Historia. Instituciones. Documentos, 40: 207-249.

PRIETO y VIVES, Antonio (1926), Los reyes de taifas. Estudio histórico-numismático de los musulmanes españoles en el siglo V de la Hégira (XI de J.C.). Madrid, Junta para ampliación e investigaciones científicas, Centro de Estudios Históricos.

SOUVIRÓN BONO, Sebastián (2012), «Imaginando el espacio: apuntes sobre la mutación de la concepción geográfica durante la Alta Edad Media», Baetica. Estudios de Arte, Geografía e Historia, 34, 315-323.

TERÁn MANRIQUe, Jonatan (2017), La explotación de la sal en el Sistema Ibérico Central durante el I milenio a.C, [Tesis Doctoral]. Zaragoza, Universidad de Zaragoza.

TYERMAn, Christopher (2019), Cómo organizar una cruzada. Barcelona, Crítica.

UtRILla UtriLla, Juan Fernando (1995), «La economía aragonesa en la segunda mitad del siglo XI: crecimiento agrícola e intercambios comerciales.» En Esteban Sarasa Sánchez, coord., Sancho Ramírez, rey de Aragón y su tiempo, 1064-1094. Huesca, IEA.

UTRILLA UTRILLA, Juan Fernando (2006), «La moneda y la circulación monetaria en el Reino de Aragón en el siglo XI: notas documentales», Aragón en la Edad Media, 19: 539-554. 